\title{
NOVOS MUSEUS, DA CULTURA DO RECOLHIMENTO À CULTURA DO EFÊMERO
}

Doris Maria M. de Bittencourt*

\section{INTRODUÇÃO}

Este texto resultante de uma pesquisa que realizei sobre "Novos Museus", na Universidade de São Paulo durante o Curso de Pós-Graduação em Arquitetura e Urbanismo. A idéia central do texto baseia-se na afirmativa de Otília Arantes, segundo a qual, "com o desenvolvimento dos meios de comunicação e o aparente triunfo da cultura de massa, teóricos e críticos dos anos 50 e 60 acreditavam que os museus logo teriam se transformado em coisa do passado. E, no entanto, estes sobrevivem e se multiplicam a um tal ponto que muitos já chamam a nossa cultura de 'cultura dos museus', vendo aí a expressão mais acabada do "espírito da época'". O objetivo do estudo foi estabelecer um elo de ligação entre estes novos espaços culturais e a sua transformação no meio cultural porto-alegrense.

* Mestre em História do Brasil - PUCRS.

Estudos Ibero-Americanos. PUCRS, v.XX, n.2, p. 85-105, dezembro, 1994 


\section{AS VANGUARDAS E O ROMPIMENTO COM A TRADIÇÃO}

A partir das reinvindicações das vanguardas dos anos 50 e 60 , que postulavam profundas transformaçōes na sociedade moderna, tornou-se impossível pensar os museus nos moldes tradicionais.

Este processo de repensar os museus, responde à uma demanda. Não é algo novo. Está presente no Estado Moderno e tem sido liderado pela França. Isto é compreensível, na medida em que a Revolução Burguesa começou oficialmemte com a Revolução Francesa. As vanguardas históricas do início do século reinvindicavam a idéia de uma ruptura radical com a história. Acreditavam que poderia começar uma nova era. Pressupunham uma concepção racionalista da história, onde haveria o triunfo da razão no tempo e no espaço, e que a conseqüência natural disso seria a justiça social e a paz. Possuíam fé no desenvolvimento cumulativo da indústria, na evolução da tecnologia e no conhecimento científico. ${ }^{1}$

Para as vanguardas históricas, a ruptura com o passado, a ordem racional da cultura e a idéia de progresso estavam relacionadas com a liberdade individual e a paz social. ${ }^{2}$

Nos anos 50 e 60, com a falência do Estado liberal, esta discussão foi retomada pela intelectualidade. Chega-se à questão dos museus. $\mathrm{O}$ denominador comum é que eles não podem permanecer nos moldes tradicionais. $\mathrm{Na}$ França, o Estado começa a assumir uma série de serviços, visando o bem estar social, é o welfare-state, o estado previdenciário, que assume uma série de medidas no campo da educação e da divulgação da cultura. $O$ processo funciona também como forma de complementar salários.

Em seu conjunto, esta política vem ao encontro a uma demanda. Ou seja, na medida em que os países vão se reerguendo e suprindo suas necessidades materiais, aumenta a procura por bens espirituais. A preocupação em criar lugares na medida das massas, não é gratuíta e corresponde a uma busca de prestígio por parte dos gestores da cultura. É algo que tem a ver com o espírito da época, que na pós-modernidade traçou novos modelos de juízos estéticos.

1 SUBIRATS, Eduardo. Da vanguarda ao pós-moderno. São Paulo: Nobel, 1986, p. 13.

2 Ibidem. 


\section{O MOVIMENTO DE INDUSTRIALIZAÇÃO DA CULTURA É LIDERADO PELA FRANÇA}

Com a França à frente do processo, tem-se uma política cultural planificada, onde as estratégias econômicas relacionam-se intimamente a uma planificação cultural com fins sociais.

Os gestores da cultura justificam os investimentos, mostrando o seu retorno do ponto de vista econômico. Não um retorno via bilheteria, mas algo mais complexo. A industrialização da cultura gera um mercado cujos benefícios revertem em benefício do país, embora sejam necessários muitos anos para se falar em lucros provenientes desse tipo de aménagement.

Se a socialização da cultura é uma questão de prestígio internacional, importa identificar até que ponto as iniciativas culturais permitem a regeneração do tecido social do entorno urbano. Até que ponto, permitem o exercício da cidadania e, atingem os objetivos sociais a que se propõem. A experiência permite verificar que as políticas das atividades sociais enquadram o indivíduo numa estrutura de afirmação do país e não oferecem instrumentos culturais que proporcionem uma autêntica vida política. Este aspecto foi analisado por Adorno, Walter Benjamin e seus discípulos.

Na medida em que a produção cultural passa a ter prestígio, além dos museus foi dada ênfase aos museus especializados, de belas-artes, aos conservatórios musicais e à high tech. La Villette, em Paris, representa esta preocupação em mostrar a sofisticação da alta tecnologia, em vários níveis. A gestão da cultura enfatiza a high culture, a grande arte e a high tech, estimulando o ponto de vista do homem comum a partir de um ponto de vista da arte elevada, ou, da cultura estetizada.

Segundo Jean Baudrillard, a high tech de La Villette não o separa do conjunto de monstros urbanos que surgiram e que vão surgir em nossos dias, e dos quais Beaubourg o protótipo. Correspondem ao destino moderno da arquitetura, consagrada à teatralidade experimental, numa cidade condenada à ditadura das normas urbanísticas. Em vez de propiciar a organicidade e a integração da cidade, a arquitetura promove a desintegração e a sua desorganização. ${ }^{3}$

Para Baudrillard, Beaubourg, Forum, Défense, Villette e Bastille não são mais objetos de comemoração, irradiação ou contemplação. Ao contrário, são lugares de absorsão e dejeção. São os lugares das máquinas de

3 BAUDRILLARD, Jean. La Villete. Belo Horizonte: "Grupo do $3^{2}$ mundo", 1989, p. 7. 
input-out put, mais próximos do Roissy do que do Louvre, embora sejam carimbadas como arte, museu e cultura. ${ }^{4}$

Se a high culture está na moda, importante que se faça distinção entre esta e a low culture. Nesta distinção, ao mesmo tempo que estimulado o consumo de massas (low culture), preserva-se uma fatia do mercado de arte para um público seleto, numa atividade elitista extremamente selecionadora.

O Beaubourg, segundo Pascal Ory representa a "metáfora da política cultural francesa", é o emblema das políticas de animação promovidas pelos Estados do capitalismo central. Otília Arantes afirma que os Estados ao mediarem a cultura, atendem a uma demanda por bens não materiais e disseminam imagens mais persuasivas do que convincentes, de uma identidade cultural e política da nação. Alguns governos restringem os orçamentos do sistema previdenciário para investir no culturel, fundindo publicidade e animação cultural. ${ }^{6}$

O welfare state se manifesta menos numa política de proteção social do que na renovação do patrimônio. Tudo se passa como se as políticas oficiais estivessem devolvendo aos indivíduos a cidadania, através de atividades lúdico-culturais em grandes centros que se tornam cada vez mais diversificados. São lugares públicos que diariamente celebram a ideologia que os anima. São substitutos de uma vida pública que deixou de existir, refletem o espírito da época e isto mais do que todo o resto, faz com que permaneçam e estejam cada vez mais presentes.?

\section{A POLÍTICA CULTURAL NOS PAÍSES DO PRIMEIRO MUNDO}

Nos países do Primeiro Mundo, a importância dada às políticas culturais relaciona-se às necessidades de afirmação nacional e regional. Este fenômeno tornou-se visível pelo seu aspecto negativo, pois incentivou um regionalismo deflagrador de violência, uma relação de exclusão fundamentalmente nociva, embora sua atuação invoque a cidadania.

4 Ibidem.

5 ARANTES, Otília. Os dois lados da arquitetura francesa pós-Beaubourg. In: Novos Estudos. São Paulo, CEBRAP, n. 22, 1988, p. 105. Citando Pascal Ory, in: L'entredeux mai; histoire culturelle de la France, mai 1968 - mai 1981. Seuil, Paris, 1983, p. 76 .

6. Idem. Os novos museus. In: Novos Estudos, n. 31, 1991, p. 164.

7 Ibidem, p. 167. 
Existe uma política cultural, que obedece a uma estratégia política dos Estados modernos e à demanda social. Porém nessa estratégia estão implícitas as diferenças. E, isto termina por afirmá-las. Cada área fica cultuando seus próprios valores. O que permanece no museu passa a ser petrificado, isolado no espaço e em sua visão do passado.

Esta violência radicalizou-se nos anos 60 , originária das vanguardas históricas dos anos 20, que pretendiam que a arte modificasse a sociedade.

O movimento levaria ao contrário, a arte terminaria por se integrar à sociedade burguesa. A partir dos anos 60 , foi retomado, por uma intelectualidade progressista, um discurso anti-estético, de ampliação do universo e do repertório cultural. Atualmente, este discurso já demonstra a sua fragilidade. Resultou na integração de tudo na lógica do capitalismo internacional. Todo esse movimento se manifesta na evolução e concepção dos novos museus.

\section{O PAPEL DO ESTADO COMO MEDIADOR CULTURAL}

Atualmente são duas as razões que explicam o significado e a permanência dos museus. O fenômeno museu é importante do ponto de vista cultural, por causa do renovado interesse pela cultura institucional. Desde a ilustração os museus são as instituiçōes destinadas divulgação da cultura.

No mundo moderno, de hoje, o Estado toma a si a mediação entre aquilo que é considerado tesouro de arte ou de história e a sua apreciação pelos cidadãoss. Considera-se responsável pela criação e organização desses espaços, que antigamente ligavam-se à grandeza e propriedades dos poderosos. $^{8}$

Segundo Ignasi de Solà-Morales, se as rebeliōes românticas, desde 1830, passando por 1968, julgavam que era possível fazer desaparecer essa mediação, hoje existe um consenso em torno da organização pública da cultura, ou seja dos museus: "Isto parece dar razão aos que, hegelianamente, impulsionavam à criação de instituiçōes, através das quais se produzisse o encontro entre os bens da cultura e seus novos e socializados usuários".

No mundo ocidental de hoje, o consumo de bens imateriais corre em paralelo com o consumo de bens materiais. Atualmente, o bem estar se

8 MONTANER, J. Maria e OLIVERAS, Jordi. Museums of the last generation. London: Academy ed., 1986, p. 86.

9 Ibidem. 
associa não só a um consumo de objetos, eletrodomésticos, carros, móveis e apartamentos, mas também se associa ao consumo de um universo de objetos simbólicos, representados pela arte, ciência, história e viagens. A construção e a proliferação dos museus a partir dos anos 50 e 60 se insere dentro desta ótica.

A segunda razão que explica o significado dos museus relaciona-se à arte propriamente dita, e sua compreensão. O museu é o instrumento de mediação entre uma realidade sem formas, imperceptível, expressa na multidão de seus objetos e a leitura dessa realidade através da ordem e da forma como esses objetos estão expostos para a compreensão. Os museus, desde a ilustração, tem sido um instrumento de interpretação da história e da arte. ${ }^{10}$

A arquitetura dos museus representa um papel muito particular nesse contexto. Hoje é um dispositivo atuante capaz de criar o ambiente físico e, ao mesmo tempo, criar um entorno simbólico, no qual se desenvolve a vida coletiva. ${ }^{11}$

\section{O PROCESSO DE MASSIFICAÇÃO CULTURAL DOS MUSEUS}

Os museus não apenas não se transformaram em coisa do passado, como sobrevivem e se multiplicam, a tal ponto que nossa cultura já é chamada de "cultura dos museus". Isto tem a ver com a expressão "espírito da época", em que está implícita a questão do esteticismo.

O processo foi descrito por Adorno e por outros pensadores que tratam do desaparecimento da cultura elevada, como uma conseqüência do processo de desestetização da arte. O momento complementar a esse processo é o de estetização da vida.

Ou seja, de uma visảo da cultura como forma, ambas mais próximas do problema da realização da pessoa, da definição de arte como experiência e expressão, do problema do sentido subjetivo da cultura. A definição da cultura como forma em sua dimensão artística e objetiva, permite a compreensão da crise da modernidade como uma crise de valores. No momento seguinte, de estetização da vida, ocorre uma experiência negativa de desvalorização dos objetivos culturais, normas, hábitos e tradições. Na desvalori-

10 Ibidem.

11 Ibidem. 
zação das formas da cultura, permanece apenas o seu lado confuso e privado de sentido. $\mathrm{O}$ homem se experimenta sob o signo do vazio. ${ }^{12}$

Segundo Eduardo Subirats o homem moderno vive perdido num mundo de símbolos e normas que mesmo possuindo uma função objetiva, estão privados de uma dimensão interior. Sente-se como um náufrago num mar de signos, que manipula e compreende, mas que não sente como parte sua. As formas e normas da modernidade são um universo frio de substâncias mortas, onde o homem experimenta a si mesmo, como uma identidade que não possui valor próprio. A crise atual da modernidade é uma crise de formas. ${ }^{13}$

$\mathrm{O}$ processo de estetização da vida liga-se à dissipação da dimensão interior de seus valores. Este processo é observado com maior clareza nos museus, considerados, como objetos portadores do significado do "espírito da época". Hoje a arquitetura dos museus esta na berlinda. Muito do "espírito do tempo" se exprime através da linguagem arquitetônica. A experiência histórica reduzida a uma fórmula, a uma sintaxe. Ocorre o desgaste das perspectivas formais das vanguardas históricas. "Os elementos cartesianos da estética neoplasticista, são esvaziados de seus conteúdos utópicos e de sua consciênicia social". ${ }^{14}$

Os museus expressam o "espírito da época" na medida em que refletem o vazio e a ausência de valores de uma sociedade que industrializou a cultura. Analisando esta questão, Adorno pensa as manifestações estéticas como algo que celebra o ritmo de uma cultura industrializada. Onde tudo é organizado e classificado, numa cultura em que para cada um é previsto algo e onde ninguém deve escapar. A indústria cultural põe fim ao particular que havia se emancipado e tornado autônomo, desde o romantismo até o expressionismo, numa revolta contra a organização. Nessa cultura industrializada o que importa é o espetáculo, a primazia dos efeitos, do exploit tangível sobre a obra. No momento anterior, teve o seu significado, no desdobramento seguinte foi totalmente liquidado. ${ }^{15}$

A linguagem arquitetônica dos museus, na atualidade, exprime muito desse "espírito da época", que exige a atrofia da imaginação e da espontaneidade do consumidor cultural. O homem vive hoje sob o signo do simulacro e do império das imagens. A sociedade do espetáculo não concretiza

12 SUBIRATS, op. cit., p. 72.

13 Ibidem.

14 Idem, op. cit., p. 74.

15 ADORNO, Teodor e HORKHEIMER. A indústria cultural. In: LIMA, Luiz Costa, (org.). Teoria da cultura de massa. Rio de Janeiro: Saga, 1969, p. 162. 
a encenação. A onipresença do simulacro veta a atividade mental do espectador, permitindo que seus produtos sejam consumidos mesmo em estado de distração. É neste momento que a linguagem arquitetônica dos museus entra como um arquétipo dessa indústria cultural, como uma arte de massa, com quem o espectador estabelece uma relação desatenta. Otília Arantes lembra que "a onipresença do simulacro também pode ser uma miragem que, ao consagrar o triunfo da pura visibilidade, na verdade arremata uma escravização do olhar à hiper-realidade imagética de caráter eminentemente táctil" ${ }^{16}$

Ao repensar as idéias de Valéry e Proust sobre os museus Adorno os considera "mausoléus" das obras de arte, como testemunho da neutralização da cultura. Para Adorno não se trata de fechá-los ou de se querer uma mise-en-scène semelhante a do objeto que se quer expor. Isto envolve um romantismo sem esperanças. Se renunciamos radicalmente à possibilidade de reinserir a obra numa tradição, cometemos um ato de barbárie por excessiva fidelidade à cultura. ${ }^{17}$

\section{O PROCESSO DE ESTETIZAÇÃO DA VIDA}

O processo de estetização da vida analisado por Walter Benjamin, que identifica componentes libertários na cultura de massas. Se a arte perdeu a sua aura, auras bastardas a substituíram. Foram criadas auras artificiais, de que resultaram o hedonismo, a neutralização do sonho e o processo de museificação. Na sociedade atual, as contradições e o culto das diferenças não são mais confrontos políticos, mas contrastes estéticos. Em relação à sociedade, fala-se numa estetização da realidade desencantada do mundo atual, estimula-se transformar o mundo em valores passíveis de admiração. Cultiva-se o culto da diversidade. O prazer que acompanha esse fato é a ausência da totalidade inteligível, o desaparecimento da distinção entre realidade e fantasia. Ao cultivar essas diferenças, o museu coloca à disposição do espectador a mais variada produçāo de obras e estilos de vida.

$\mathrm{Na}$ medida em que a obra de arte perde a sua função ritualista, passa a ter maiores condições de ser exposta. Isto faz com que perca a sua aura. A

16 ARANTES. Arquitetura simulada, conferência pronunciada na FUNARTE, em outubro de 1987, incluída na coletânea $O$ olhar. São Paulo: Companhia das letras, 1988 , p. 257.

17 ADORNO. Valéry, PROUST, Musée. In: Prismes. Paris: Payot, 1986, p. 153. 
arquitetura, como invólucro para as obras de arte, percorre um sentido aparentemente inverso. Passa a revestir-se de uma parafernália de formas, numa tendência monumentalista, mas permanece com o mesmo sentido de perda de significado. Coloca-se frente ao espectador como uma arquitetura de massas, oferecendo-se à recepção coletiva e estabelecendo com o espectador uma relação de distração em sua apreensão, ${ }^{18}$ "a fruição táctil faz-se menos por via da atenção do que por via do hábito". ${ }^{19} \mathrm{~A}$ arquitetura prossegue em seu caminho rumo à espetacularização, pretendendo deixar de ser o invólucro para as obras de arte e disputando com elas a condição de obra de arte total.

O Museu de Monchengladbach, de Hans Hollein, um exemplo dessa arquitetura que pretende ser obra de arte total. Possui aberturas, onde as obras de arte expostas, são alternadas por janelas que se abrem para a rua, trazendo a cidade para dentro do museu. Às vezes, um espelho que se reflete através de uma janela. É o retorno cidade, o poder de extroversão dos museus, que tem como componente a petrificação da cidade. Em Monchengladbach há um rebatimento entre a experiência no museu e a experiência na cidade. Isto faz com que os gestores lancem mão disto, no sentido de reativá-la, objetivando criar identidades culturais que permitam ao grupo social ter um papel histórico. Em alguns espaços do museu ocorre a inversão: as obras de arte são escolhidas em função do espaço interno criado no museu e no sentido de valorizá-lo.

O Museu D'Orsay, em Paris é o mais pós-moderno dos museus. O prédio se impõe de tal maneira que as obras são secundárias. Ocorre um recurso à obra como elemento de decoração. Outro exemplo de inversão é o Museu da Escultura, em São Paulo. O museu é subterrâneo e a iluminação é artificial, inadequada para esculturas. Mesmo que tenha preocupações plásticas, o arquiteto Paulo Mendes da Rocha volta ao museu como mausoléu.

Os gestores da cultura estimulam essa política estético hedonista. Estimula-se não apenas a valorização do patrimônio arquitetônico, mas a valorização dos espaços, que agora são cenários onde acontecem comportamentos diferenciados. O status é dado não só pelas pessoas, mas tem a ver com o cenário que freqüentam. É um estilo de vida que coincide com o cenário em que esta vida é representada. O museu é o gerador da vida

18 ARANTES. Arquitetura... p. 259.

19 BENJAMIM, Walter. A obra de arte na época de sua reprodutibilidade. In: LIMA, op. cit., p. 236. 
estetizante. Esta contaminação entre vida social, mundanidade e arte se reflete em diversas instâncias: na vitrine de uma loja em Londres, não interessa o produto que alguém quer comprar. A ênfase não é dada no objeto. Consome-se a griffe. É uma proliferação de imagens que faz com que o espectador consuma algo.

Este comportamento passa para o político. Se a vida passa por uma criação de imagens, a vida política passa por uma estetização. Se há algo de positivo nestes museus, com a cultura em alta, é indiscutível também que se tem um jogo de interesses políticos. $\mathrm{O}$ universo estetizante impede que venham à tona os interesses políticos encobertos.

A frivolidade e o efêmero definem muito do espírito da época. Assiste-se ao interesse estético substituindo a paixão política. A linguagem atual é frívola porque ela separa o significante do significado. Sintomaticamente, o significado da existência dos museus na atualidade se insere no âmago deste jogo de símbolos que definem o espírito da época.

\section{A MODA: O IMPÉRIO DO EFÊMERO}

Gilles Lipovetsky, em $O$ império do efêmero, analisa essa situação limite, que é uma caricatura da cultura contemporânea. Ele considera a moda como uma atividade prestigiosa. Para o autor, os objetos e a cultura de massa são tomados pela lógica do novo, por uma turbulência que pode não ser idêntica à da moda, mas não é menos análoga à desta. As sociedades democráticas ordenam-se pelo efêmero e pelo superficial. Da ideologia contestatória e hiper-crítica dos anos 60 e 70, pouco restou. Acabou a era das profecias seculares. Em algumas décadas, os discursos revolucionários foram varridos, perderam toda legitimidade e apoio social. A partir do momento em que desaba a crença numa verdade absoluta da história, instala-se um espaço efêmero, móvel e instável. As interpretações graves do momento anterior são substituídas pela "embriaguez leve do serviço do consumo instantâneo". O processo de dessacralização e de dessubstancialização. E a moda define esse processo: a forma moda traduz o terminal da democratização do sentido e dos espíritos. ${ }^{20}$

A arquitetura dos museus, em seu momento pós-moderno, obedece ao mesmo processo. Valorizando a retomada do passado e a tradição artística

20 LIPOVETSKY, Gilles. $O$ império do efêmero. São Paulo: Companhia das Letras, 1991, p. 241. 
"remata seu devir moda": reina o ecletismo, não é imperativo uma ruptura com o passado. Misturam-se o antigo e o novo. A arquitetura entra no imperativo da moda. Não se exclui: recicla-se. Aliviada do código da ruptura modernista, a arquitetura fica sem pontos de referência. Agora, é um valor comandado mais pela moda do que pelas vanguardas históricas. E aqui, mais uma vez, sabemos porque os novos museus vieram para ficar e são a expressão mais acabada do espírito da época. ${ }^{21}$

\section{OS NOVOS MUSEUS: DO RECOLHIMENTO À DISTRAÇÃO}

Otília Arantes, em seu texto sobre Os novos museus, mostra como nos anos 50 e 60 a cultura era trazida para o cotidiano e, agora, como o cotidiano vai à cultura, se desestetiza a arte e se estetiza o cotidiano. A isto é fundamental acrescentar: a melhor expressão deste processo são os museus. $^{22}$

Nos anos 50 e 60 os críticos e teóricos acreditavam que os museus logo se transformariam em coisa do passado. Isto não ocorreu porque os museus se transformaram na melhor expressão do processo de desestetização da arte e estetização do cotidiano.

No mundo atual não existe mais arte, é importante assinalar como a arquitetura é protagonista e, ao mesmo tempo, sintoma desse processo de esvaziamento da arte. Jean Baudrillard analisa o Beaubourg, "metáfora da política cultural francesa", ${ }^{23}$ frisando o compromisso que os novos museus têm com a política de seus gestores. Ao mesmo tempo frisando como isto tem a ver com o processo de estetização do cotidiano, onde a arte funciona como um policiamento do social.

Para Baudrillard a arquitetura do Beaubourg evoca uma sensação de irrealidade. É obcena, na medida em que leva ao êxtase, à cegueira, ao domínio da comunicação plena, que não comunica mais nada. É o universo absolutizado, saturado e sem sentido. Para ele o Beaubourg é um cenário onde não existe mais encenaçāo, onde o público não é mais público. A massa que circula pelo Beaubourg é como um écran insensível, como uma placa que nāo está mais sujeita a qualquer tipo de manipulação. É um monumento

21 Ibidem.

22 ARANTES. Os novos museus, op. cit., p. 167.

23 Idem. Os dois lados..., op. cit., p. 76. 
aos jogos de simulação de massa, um grande incinerador absorvendo toda a energia cultural e devorando-a. ${ }^{24}$

O Beaubourg é sobretudo uma máquina de fazer o vazio. A suprema contradição que possui exteriores modernos e interiores ancorados em soluçōes tradicionais. Para Baudrillard, ele é: "monument ou un anti-monument équivalent da l'inanité phallique de la Tour Eiffel en son temps. Monument à la déconnection totale, l'hyperréalité et l'ímplosion de la culture". ${ }^{25}$

Para Baudrillard, no Beaubourg ocorre o êxtase da comunicação, que corresponde à fascinação. O comportamento das massas no fascínio do êxtase da comunicação, numa sociedade da hiper-comunicação que nada mais comunica, leva ao limite do vazio.

Nesse universo da fascinação não existe mais sedução, o público não toma partido e não reage, pois a massificação implica num aniquilamento total da cultura, do saber, do poder e do social. Nesse processo de aniquilamento da cultura Baudrillard vê um lado positivo no comportamento das massas, que vão ao Beaubourg para assistir aos funerais da própria cultura. Para provocar, literalmente, a "catástrofe" do Beaubourg, o grande centro concebido na medida das massas, o grande "shoping", onde a massa pōe fim à própria cultura de massa. A hora do simulacro não se sustenta onde não existe distinção entre significante e significado.

Com o desenvolvimento dos meios de comunicação, os museus transformaram-se, e esta transformação tem sido fundamental para a sua permanência. A partir dos anos 60, a cultura e a tecnologia da comunicação entram para os programas dos museus. O museu passa por um processo de dessacralização deixando de ser um lugar de contemplação da obra de arte para abrigar cinemas, estúdios, bibliotecas, salas de vídeos, salas para banquetes e até night clubs. A relação de consumo não se estabelece de forma imediata como nos shopings centers, mas os museus aos poucos vão assumindo funçōes de consumo, com espaços para venda de catálogos, reproduções, cafeterias e restaurantes. Estes se convertem em grandes atrativos para o público.

A grande modificação ocorreu, efetivamente, nos programas dos museus. Paralelamente, os museus tradicionais precisaram ser reciclados para se transformarem na nova arquitetura à medida das massas. As intervenções de I. M. Pei and Partners, no Grand Louvre, (1983) e a ampliação 
do Museum of Modern Art de New York, (1977-1984), consistiram numa redistribuição dos acessos e circulações, ampliando os espaços de exposiçōes e proporcionando novos servicos. ${ }^{26}$

No caso da ampliação por I. M. Pei (1978-1984) da National Gallery, em Washington, um grande hall foi acrescido ao antigo prédio e o programa tornou-se complexo: espaços para exposições, cafeterias, restaurantes, auditório, administração, estudos de arte avançada, bibliotecas e laboratório. ${ }^{27}$

Na Staatsgalerie, em Stuttgart, (1977-1984), de James Stirling, as dependências resultantes das novidades do programa adotam cada uma a sua forma particular e se articulam em torno a um grande $\mathrm{U}$ do sistema do museu tradicional. Stirling usa uma grande diversidade de formas para responder complexidade do programa. ${ }^{28}$

No entanto, a grande novidade a partir dos anos 50 e 60 são os museus da ciência e da técnica, que estão plenamente sintonizados com o espírito da época. Destinados a colecionar objetos da produção industrial, "alguns exploram as vertentes mais participativas dos edifícios culturais". ${ }^{29}$

Um dado marcante nos museus de ciências e tecnologia é que o valor da obra de arte com sua aura desaparece por completo. Destes o arquétipo é o Museu da Ciência e da Técnica em La Villette (1980-1986), em Paris. Conforme já assinalamos, Baudrillard não lhe poupa críticas:

"Não se arrisca a arquitetura em se tornar residência secundária do espaço, um asilo espacial em última instância. Há um risco da arquitetura como simples terapêutica do espaço, como se este fosse uma forma em extinção ou um doente. A arquitetura, como a pedagogia ou o poder. se esforça em desaparecer para deixar transparecer, não sei que verdade, que nada estaria pedindo, a não ser surgir e falar". ${ }^{30}$

Em todos os museus de ciências, os espaços são homogêneos, neutros e flexíveis, de forma a permitir constantes mudanças de exposições. Ainda dentro dessa ampla abertura, surgiram os ecomuseus.

Uma das preocupações que marcou a política cultural a partir dos anos 60 foi a ampliação das atividades dos museus. Além dos bens culturais, os museus passaram a abrigar atividades mais prosaicas. $O$ freqüentador passou

26 MONTANER, op. cit., p. 10.

27 Ibidem.

28 Ibidem.

29 Idem, p. 11.

30 BAUDRILLARD, La Villette, op. cit., p. 3. 
a ser solicitado a participar de forma mais criativa. Eram os ateliês, as salas de conferências e a combinação de atividades pedagógicas e lúdicas.

\section{O MODELO DA ARTE É A MODA}

Com André Malraux, as Casas de Cultura permitiam às pessoas desfrutar da high culture, não longe de suas casas. Em todo núcleo urbano havia espaços alternativos. Essa função pedagógica e lúdica dos museus, entretanto foi logo esgotada. Agora, os museus trazem a proposta de atender a uma população sem o compromisso de fazer nada. Se os museus mantém os seus cursos e atividades tradicionais, não esqueçamos, que possuem atividades extremamente mundanas como night clubs ou espaços para eventos políticos. A tendência tem sido trazer grandes empreendimentos para as cidades, para que elas tenham uma vida cultural intensa e polarizem um grande número de pessoas.

Entretanto, a evolução da arte nos anos 50 e 60 trouxe definitivamente as grandes inovações para os museus. As mudanças no conceito de obra de arte colocaram em crise o próprio espaço do museu. O conceito tradicional de obra de arte passou a ser questionado. Ocorreu uma redefinição pública da arte e uma redefinição da própria vida. A arte passou a ser pensada a partir de uma pluralidade de estilos de vida. Segundo Jeudi, isto pressupoe uma reformulação positiva da sociedade.

Neste momento passaram a ter importância os hapennings, os eventos fartamente documentados, mas que não perduram, as performances que acontecem fora dos espaços dos museus. Hoje, arte e moda não se distinguem. É o efeito rápido, o paradoxo. A idéia é criar o pseudoacontecimento. A arte está regida pela ótica da moda e do vazio. O modelo da arte é a moda. Em função destas transformações, os museus precisam se reestruturar. Dilatam-se para abranger novas funções.

A arquitetura dos museus, da mesma forma que a arte assume a dualidade: ao mesmo tempo que rompe com o moderno, cultiva o progresso e a técnica. A arquitetura evolui de tal forma, que de invólucro para as obras de arte, transforma-se no próprio conteúdo. O rompimento com a própria arte é feito em nome do progresso e da técnica. Esse processo de ruptura e de esvaziamento faz parte da lógica do capitalismo avançado. 


\section{OS MUSEUS-MONUMENTO}

Atualmente as políticas culturais englobam os acervos culturais e sociais. Nelas, está embutida além da questão dos museus, sua arquitetura e sua permanência, a questão do patrimônio: ou seja, os museus permanecem também por serem úteis às políticas culturais de preservação do patrimônio e de valorização do contexto. Os gestores da cultura escolhem determinados objetos pertencentes a um patrimônio histórico, para ali exercerem as intervençōes necessárias a sua transformação em museus, em geral em museus-monumento.

Para isto possuem diversas motivações. O patrimônio remete a uma visão de cultura e a idéia de sua conservação, invariavelmente remete à promoção dos gestores da cultura e renovação da clientela.

O patrimônio é um objeto cultural, mas também um objeto de uso cotidiano. Enquanto espaço urbano, é um produto submetido ao processo de compra e venda. Quando localizado nos centros das cidades, tem melhor acessibilidade aos bens e serviços. É um produto urbano de alta qualidade e um instrumento de publicidade social. O patrimônio exposto torna-se uma forma de propaganda da qualidade da cidade. Ele evoca o sentimento de pertencer a uma determinada cultura, mobiliza o sentimento de fidelidade e de coesão por parte de seus habitantes. Neste sentido é superior a qualquer tipo de exposição sobre a cidade. É uma forma de propaganda que expressa um novo modo de gestão dos signos por parte dos gestores da cultura. ${ }^{31}$

As intervenções em objetos pertencentes ao patrimônio para transformá-los em museus, por um lado, se trazem implícita a possibilidade de regeneração ou valorização dos contextos, por outro, não deixam de funcionar como publicidade para os gestores da cultura. A idéia é transformar em museus, antigos prédios históricos, objetos nobres, símbolos de um poder institudo (castelos, igrejas, hotéis particulares, principalmente) em torno dos quais se mobiliza uma classe que se considera culta, uma burguesia ou pequena burguesia, regenerando o tecido urbano onde se localizam.

Por si sós, os museus dificilmente conseguiriam recuperar o contexto urbano. Não são apenas estes museus monumentos que contribuem para a recuperação das áreas: é preciso uma visão de conjunto e uma valorização da arquitetura vernacular. Isto passa pela recuperação para a habitação, de

31 DAVALLON, Jean (org). Claquemurer pour ainsi dire tout l'univers. Paris: Centre G. Pompidou, 1986; cf. em especial Annie GOTMAN, "L'entreprise municipale de patrimoine", p. 126. 
zonas centrais ou periféricas das cidades, próximas a estes museus. Passa também pela preservação e modernização dessas áreas em decomposição. Os espaços devem ser preservados, mesmo que suas funções mudem em relação ao que era antes, o importante é que tenham suas funções inseridas nas atividades da cidade.

O Museu d'Orsay, em Paris, é uma intervenção num prédio de valor histórico, funcionando como elemento revitalizador da área. É emblemático no sentido de corporificar uma espetacularização da cultura e da arte, em sintonia com o espírito da época. Patricia Mainardi afirma que Orsay sintetiza a resolução das oposições entre arte e política. Nele convivem arte histórica e conceitos museográficos em oposição a revisionismo e teoria arquitetônica pós-moderna. ${ }^{32}$

A Gare d'Orsay, construída em 1898, por Victor Laloux, teve seu exterior renovado por A.C.T. Architecture (Renaud Bardon, Pierre Colboc, Jean-Paul Philippon) enquanto o interior foi desenhado pelo arquiteto Gae Aulenti. A estação de trem era um anacronismo. Deixou de funcionar em 1939 e teria sido demolida em 1971, quando foi salva pelos clamores daqueles que desejavam preservar a arte do século XIX. ${ }^{33}$

A intervenção pesada deixou o espaço menor e pretendia estabelecer uma distinção entre o lugar de passagem que era a estação de trem e o lugar onde se vai para ficar. A visão de história, tal como revista em Orsay, muito mal contada, resumindo-se à convivência de obras e estilos do século XIX, numa verdadeira mistura descriteriosa.

\section{OS NOVOS MUSEUS EM PORTO ALEGRE: A CASA DE CULTURA MÁRIO QUINTANA E A USINA DO GASÔMETRO}

No Brasil a preocupação com museus e centros culturais é reflexo do que está acontecendo nos países do Primeiro Mundo.

Em Porto Alegre, Rio Grande do Sul, houve dois casos de reciclagem de prédios históricos. Nenhum foi transformado em museu. Mesmo assim, exemplificam a relação citada acima. O primeiro deles a Casa de Cultura Mário Quintana e o segundo, a Usina do Gasômetro.

MAINARDI, Patricia. Postmodern history at the musée d'Orsay. In: October, NY, n. 41,1986, p. 32.

33 Ibidem, p. 33. 
A Casa de Cultura Mário Quintana, cuja intervenção ficou a cargo dos arquitetos Flávio Kiefer e Joel Gorski, foi inaugurada em 1990. Originalmente, era o Hotel Majestic, projeto de 1910 do arquiteto alemão Theo Wiedersphan. Numa solução avançada para a época, Wiedersphan criou dois blocos, separados por uma rua. O espaço aéreo da via ocupado por passarelas que interligam os blocos. É um prédio prestigioso que testemunha o fausto e grandeza da cidade no período anterior à Primeira Guerra Mundial. A Casa de Cultura Mário Quintana não foi proposta na medida das massas. Relacionando-se mais ao espírito das casas de cultura concebidas por André Malraux, na França. Possui um caráter acentuadamente elitista e uma dimensão pedagógica de divulgação da cultura. Com espaços excessivamente autônomos, tem falta de integração em suas atividades. De interesse da coletividade, sua restauração rendeu dividendos a seus gestores. Hoje, sofre exatamente por falta de uma política cultural mais efetiva.

A Usina do Gasômetro era uma fábrica para produção de gás hidrogênio para iluminação pública. As primeiras instalaçōes datam de 1874 . Segundo Sérgio da Costa Franco, o primeiro gasômetro funcionou na Praia do Riacho, hoje Washington Luís, quando iluminava a cidade com seus 500 combustores. Atualmente sua história esta sendo pesquisada pela historiadora Luiza Helena Kliemann. A remodelação da Usina, concebida na gestão do PT (Partido dos Trabalhadores), tem uma atividade de massa, voltada para os trabalhadores. Segundo seus gestores um marco referencial para os trabalhadores se expressarem das mais diversas formas, onde atuam três agentes culturais: os sindicalistas, o movimento popular e o movimento dos artistas.

A intervenção na Usina ficou a cargo do arquiteto Marco Schuch, ocorrendo na obra algumas citações a Lina Bo Bardi.

Ambos são exemplos típicos de prédios que projetam um sentimento de pertencer a determinada região, diferenciada do resto do país e estimulam um sentimento de fidelidade e coesão. Ambos fazem parte de um projeto de revitalização do centro da cidade. Sāo cartōes de visita que funcionam como marketing para seus gestores.

\section{A DISTÂNCIA ESTÉTICA É RESOLVIDA NUM FETICHE ÀS AVESSAS}

Retomando a análise de Adorno sobre a autonomia da obra de arte, observamos que sua análise gira também em torno da concepção atual dos 
museus. Para Adorno a arte renega sua autonomia, na medida em que se torna bem de consumo. Seu caráter autônomo só era possível enquanto negava seu conteúdo de mercadoria. Mesmo aí estava sujeita aos ditames dos comitentes. Hoje "a liberdade dos fins da grande arte moderna vive do anonimato do mercado", ${ }^{34}$ a arte pode não ter finalidade desde que sua "finalidade" seja o mercado. Assim Adorno afirma que:

"Adequando-se por completo à necessidade, a obra de arte priva por antecipação os homens daquilo que ela deveria procurar: liberá-los do princípio da utilidade. Aquilo que se poderia chamar o valor de uso na recepção dos bens culturais substituído pelo valor de troca, em lugar do prazer estético penetra a idéia de estar em dia, em lugar da compreensão, ganha-se prestígio". ${ }^{35}$

Esta idéia de substituição do prazer estético por prestígio revivida na relação do espectador com a obra de arte nos museus atuais. Benjamin frisava que era lugar comum o fato das massas quererem diversão, e a obra de arte exigir recolhimento. Para ele a oposição entre arte e divertimento se explicitava no seguinte:

"Quem se recolhe diante de uma obra de arte é envolvido por ela, penetra nela tal como o pintor chinês que, segundo a lenda, perdeu-se na paisagem que acabara de pintar: no caso da diversão, pelo contrário, a obra de arte que penetra na massa, nada mais significativo, a este respeito, que um edifício. Em todas as épocas, a arquitetura nos apresentou modelos de uma obra de arte só fruida na diversão e de modo coletivo". ${ }^{36}$

Hoje sabemos porque a postura de recolhimento do espectador diante da obra de arte é impossível, tudo é pensado na medida do consumo. A relação de recolhimento é substituída pelo esfriamento proposital. Hoje os museus são pensados como "monumentos" que se opōem aos museus tradicionais (templos da cultura). São projetados de forma a sobrepujarem as obras que envolvem, enquanto atrativo para o grande público. Segundo Otília Arantes a distância estética é resolvida num fetiche às avessas. A cultura do recolhimento é administrada como um descartável: nos museus atuais, se o exterior é high tech, o interior é tradicional. ${ }^{37}$

ADORNO, A indústria..., op. cit., p. 192.

Ibidem, p. 193.

BENJAMIM, op. cit., p. 235.

37

ARANTES. Os dois lados..., op. cit., p. 106. 
Atualmente a arquitetura dos museus toma a forma de imagem publicitária e os arquitetos se interessam pelo poder. Ao se constituírem os museus recorrem ao star system da arquitetura. Os arquitetos para terem prestígio almejam projetar um museu. Importa produzir algo ligado high culture. Importa também a valorização do monumental. Entre os new moderns, Richard Meyer é considerado o maior. O detalhe importante é que essa arquitetura não possui nenhuma perocupação social. James Stirling, não vê inconveniente algum em comparar a linguagem arquitetônica dos museus a dos shopings centers. Assim a linguagem arquitetônica moderna se "condensa numa única imagem, que é o último estágio da forma mercadoria. cuja generalização e reprodução o estado tem por função assegurar". ${ }^{38}$ Os administradores franceses sonham com o dia em que o Louvre ser mais conhecido que a Coca-Cola. ${ }^{39}$

O Louvre simboliza a pureza da forma transformada em monumento. Nele a ênfase no monumental se realiza sobre uma referência tipológica clara, que tem por objetivo recuperar a idéia dos espaços monumentais da história. Segundo Pei, seu autor, é um monumento invisível, cuja referência é a pirâmide egípcia de Giseh. Se esta celebrava a morte, para Pei a pirâmide do Louvre, é transparente no sentido de celebrar "a luz" que é levada aos visitantes: "esta pirâmide é uma pura forma geométrica, uma forma cristalina, uma forma natural no nosso universo. Em chinês esta forma significa o 'pagode de ouro'. É uma forma clássica". ${ }^{40}$

Nos últimos dez anos os museus, expressam cada vez mais a sua vocação para representarem monumentos que irão revitalizar as cidades, e que tomam como referência a própria cidade. Outro exemplo, já citado a Staatsgalerie de James Stirling. O projeto toma como principal referência a praça e os passeios de pedestres. Inspirado no projeto Altes Museum, construído em Berlim, em 1823-1830, por Friedrich Schinkel, a Staatsgalerie possui um caráter de monumentalidade e, paralelamente apresenta uma solução tradicional em seu interior, com a organização da galeria em torno da grande rotunda central.

38 Ibidem, p. 121.

39 Ibidem.

40 Ibidem, p. 112. 


\section{CONCLUSÃo}

Concluindo, os museus mudaram porque também mudaram as relações do espectador com a obra de arte. A cultura do recolhimento foi substituída pela cultura do efêmero. Os museus são somente os sintomas de uma civilização que industrializou sua cultura. Expressam o "espírito da época", a política cultural de seus gestores e a busca de formas simbólicas e monumentais para a arquitetura realizar-se como "arquitetura de massas".

Considerando a grande diferença existente entre os países do Primeiro Mundo e do Terceiro Mundo, não é possível adotar para ambos, o mesmo tipo de avaliação a respeito das políticas culturais e da implantação dos "novos museus". Embora, devamos estar conscientes do que elas representam.

No Sul, dada a carência de espaços para atividades culturais, a política de implantação dos "novos museus" é sempre bem-vinda, mesmo que comprometida com a política dos gestores da cultura. Desde que não seja instrumento para reafirmar regionalismos deflagradores de violência e relaçōes de exclusão fundamentalmente nocivas, baseados nas singularidades da cultura sul-rio-grandense. E, desde que se procure sempre preservar a high culture no sentido de torná-la cada vez mais acessível a um número maior de pessoas. Ou melhor, importa que a socialização da arte não se contente nunca com a tarefa mais fácil, de nivelar pela low culture, ou de elitizar a obra de arte.

Paralelamente é importante que se resgate efetivamente para os espaços culturais citados, a Casa de Cultura Mário Quintana e a Usina do Gasômetro, o espírito que presidiu a fundação das casas de cultura de André Malraux, e que permitia às pessoas desfrutarem da high culture, não longe de suas casas, que se resgate a função pedagógica e lúdica dos museus.

Quanto à arquitetura dos museus, é importante que se compenetre de seu verdadeiro papel, e não percorra o caminho da contra-mão da obra de arte. A arquitetura não deve se impor de forma a que as obras de arte a serem expostas se tornem secundárias. Pois afinal, os museus devem existir como invólucro para a obra de arte e não o contrário. Embora o uso da linguagem monumental na arquitetura seja tentador para muitos arquitetos, o profissional de arquitetura deve ter extremo cuidado e avaliar até que ponto é válido adotar para os museus a mesma linguagem monumental dos shopings centers. 


\section{BIBLIOGRAFIA}

ADORNO, Theodor. Valery, Proust, Musée. In:_— Prismes. Paris: Payot, 1986. (p. 152-63). cultura de massa. Rio de Janeiro: Saga, 1969.

ARANTES, Otília. Os dois lados da arquitetura francesa pós-Beaubourg. In: Novos Estudos, São Paulo: CEBRAP, n. 22, 1988 (p. 102-34).

—. Os Novos Museus. In: Novos Estudos, n. 31, 1991 (p. 161-9).

. Arquitetura Simulada. In: $O$ olhar. São Paulo: Companhia das Letras. 1988, (p. 257-82).

ARCHITECTURE AND URBANISM, Extra Edition. James Stirlng/Michel Wilford and Associates, may, 1990.

BAUDRILLARD, Jean. L'effet Beaubourg. Paris: Galilée, 1977. . La Villette. Belo Horizonte: Grupo Céu do $3^{\circ}$ Mundo, 1989.

BENJAMIN, Walter. A obra de arte na época de sua reprodutibilidade técnica. In: LIMA, op cit.

DAVALLON, Jean (org.). Claquemurer pour ainsi dire tout l'univers. Paris: Centre G. Pompidou, 1986; cf. em especial Annie GOTMAN. "Léntreprise municipale du patrimonie", (p. 127-83).

FRANCO, Sérgio da Costa. Porto Alegre, Guia Histórico. Porto Alegre: UFRGS/Prefeitura Municipal de Porto Alegre, 1988.

GRANDS TRAVAUX. Special issue of "connaissance des Arts". English Edition.

LIPOVETSKY, Gilles. L'ère du vide.

. O Império do efêmero. São Paulo: Companhia das Letras, 1991.

MAINARDI, Patricia. Postmodern History at the Musée d'Orsay. In: October, NY, n. 41, 1986, (p. 30-52).

MELO, Hygina Bruzzi de. A cultura do simulacro: filosofia e modernidade em Jean Baudrillard. São Paulo, Loyola, 1988.

MONTANER, J. Maria e OLIVERAS, Jordi. Museums of the last generation, London: Academy ed., 1986.

PARACHUTE, n. 46, Montréal, 1987. "Musées/museums"; cf. em especial entrevista com Joannes CLADDERS sobre o museu de Monchengladbach, (p. 45-99). . POINSOT, Jean-Marc. Quand l'oeuvre a lieu. (p. 70-77).

PARIS 1979-1989. New York: Rizzoli, 1988.

PROJETO n. 144, 1991. Museus, duas décadas.

SEARING, Helen. The development of museum Typology. In: STEPHENS, Suzanna (org.). Building the new museums; the archtectural leage of New York. Princeton Architectural Press, 1985.

SUBIRATS, Eduardo. Da vanguarda ao pós-moderno. São Paulo: Nobel, 1986.

WEIMER, Gunter. Theo Wiederspahn, arquiteto. In: PROJETO, n. 80.

WERT, José Ignacio. Las musas y las masas. In: Arquitetura viva. Barcelona, n. 24, May-Jun, 1992. 